\title{
Editorial Contexto \& Educação 100 - Saberes e Conhecimentos em Educação
}

A publicação do número 100 da Revista Contexto \& Educação é uma conquista resultante do esforço de diferentes autores, que confiam e confiaram na circulação de ideias possibilitada por este periódico. O professor Mario Osorio Marques, primeiro editor da Revista, criou um espaço para publicação de pesquisas e ensaios, que constituem o acervo deste periódico, desde abordagens de Educação Popular; Desenvolvimento de Currículo; Formação Docente; Teorias Pedagógicas; Educação Ambiental e em Saúde; Ética e Educação; Educação Republicana; Diversidade; Estudos sobre Gênero, até o ensino nas áreas específicas (Ciências, Geografia, Matemática, História, Letras,...). Essa diversidade teórica embasa muitas das discussões do Programa de Pós-Graduação em Educação nas Ciências (PPGEC).

Os artigos deste número, marcados pela originalidade das reflexões propostas, tratam de saberes e conhecimentos em educação desde uma visão cognitiva, semiótica e hermenêutica, de educação ambiental, popular até as questões de inclusão.

No artigo Cognição, semiótica e modelagem: articulações possíveis, Zulma Elizabete de Freitas Madruga, Guy Barros Barcellos, José María Chamoso e Valderez Marina do Rosário Lima escrevem um ensaio abordando as teorias da cognição, semiótica e modelagem, com o objetivo de articulá-las e encontrar pontos convergentes que possam auxiliar no processo de ensino e aprendizagem escolar.

Em Compreensões acerca da hermenêutica na análise textual discursiva: marcas teórico-metodológicas à investigação, Robson Simplicio de Sousa e Maria do Carmo Galiazzi apresentam elaborações acerca da influência da hermenêutica na Análise Textual Discursiva (ATD), num exercício de metanálise da obra de Moraes e Galiazzi (2007) em busca dos aspectos hermenêuticos desta metodologia de análise, que está vinculada a Hans-Georg Gadamer. 
A Educação Ambiental foi tematizada em três artigos. No primeiro, Tatiane Cristina Possel Greter Schwingel, Rosangela Ines Matos Uhmann, Erica do Espirito Santo Hermel refletem sobre As (im)possíveis relações ambientais versus conceituais em livros didáticos de ciências do $6^{\circ}$ ano do Ensino Fundamental, a partir da análise de Livros Didáticos (LD) de Ciências. No segundo artigo, intitulado Transformación urbana y fronteras imaginarias en el Valle de Santiago durante la Conquista española (Siglo XVI), Daniela Derosas escreve sobre as cidades americanas, que se constituíram a partir do século 16 como espelho da Espanha e da imposição dos conquistadores. Num contexto diferente, transformam a paisagem e criam um tecido urbano dissociado do ambiente. Por último, o texto La evolución histórica de los elementos nocivos en el medio ambiente de Madrid, de Salama Seleima, aborda a influência da poluição ambiental no mundo, desde os primeiros anos da Revolução Industrial até os dias atuais, evidenciando os elementos nocivos e sua evolução na cidade de Madrid.

$\mathrm{O}$ artigo seguinte pontua os aspectos ambientais e de educação popular formal. Orildo Ribeiro Santos relata no texto Um olhar de alunos da EJA sobre impactos ambientais do turismo costeiro em Ajuruteua (Bragança-PA), as concepções apontadas pelos alunos da EJA sobre este tema desde as suas demandas e dos turistas que visitam a região.

Paulo Alfredo Schönardie e Liria Ângela Andrioli ocupam-se do tema Uma experiência popular de educação: o fórum gaúcho da juventude, construída pela juventude no Fórum Gaúcho da Juventude (FGJ), como protagonistas deste espaço educativo.

Em Os três momentos pedagógicos como estruturantes de currículos: o tema infraestrutura a partir do estudo da realidade, Laís Baldissarelli e Cristiane Muenchen analisam o processo de construção curricular de uma escola da rede pública da cidade de Santa Maria/RS.

Neusete Machado Rigo, por sua vez, em seu artigo Desdobramentos da política nacional de educação especial na perspectiva da educação inclusiva em políticas locais, investiga os impactos que a Política Nacional da Educação Especial na perspectiva da Educação Inclusiva/2008 (Seesp/MEC) provocaram na organização das políticas municipais e escolares para a construção de escolas inclusivas. 
No artigo Um Modelo da Arquitetura Mental de Inferência dos Estímulos Sensoriais Para o Ensino de Surdos, Rubens dos Santos Guimarães, Válter Strafacci, Paulo Marcelo Tasinaffo e Eliete Guimarães Vasques organizam um modelo conceitual de Arquitetura Mental Digitalizada - AMD, que possibilita reproduzir inferências sobre estímulos sensoriais de surdos, focada na instituição de um sistema web, para melhorar o processo de ensino e aprendizado de alunos com desabilidade auditiva.

Essa diversidade teórica embasa muitas das discussões do Programa de Pós-Graduação em Educação nas Ciências (PPGEC) e de outros programas de Educação e Ensino do Brasil, Chile, Colômbia, Costa Rica, Espanha, Peru, Portugal, Alemanha, França, com quem dialogamos e de quem recebemos submissões de artigos. Estes movimentos teóricos vivenciados, nesta interlocução contínua, representada pela publicação destes cem números, possibilitam o reconhecimento e a qualificação da revista.

Esperamos que vocês leitores desfrutem das reflexões propostas pelos autores.

Maria Cristina Pansera-de-Araújo

Celso José Martinazzo

Solange Schorn 